\title{
Observations of shallow convective clouds generated by solar heating of dark smoke plumes
}

\author{
L. Klüser ${ }^{1}$, D. Rosenfeld ${ }^{2}$, A. Macke $^{3}$, and T. Holzer-Popp ${ }^{1}$ \\ ${ }^{1}$ German Aerospace Center (DLR), German Remote Sensing Data Center (DFD), Weßling, Germany \\ ${ }^{2}$ Institute of Earth Sciences, Hebrew University of Jerusalem, Jerusalem, Israel \\ ${ }^{3}$ Leibniz-Institute of Marine Sciences, IFM-GEOMAR, Kiel, Germany
}

Received: 22 November 2007 - Published in Atmos. Chem. Phys. Discuss.: 10 January 2008

Revised: 26 March 2008 - Accepted: 12 May 2008 - Published: 29 May 2008

\begin{abstract}
The SEVIRI instrument on the Meteosat Second Generation satellite with both fine spatial and temporal resolution allows to detect and follow the dynamics of fast developing meteorological events like spreading smoke plumes and the lifecycles of convective clouds. Smoke plumes have the ability to change the atmospheric heat content due to absorption and reduced reflection of solar radiation. By these means they can trigger formation of shallow convective clouds at their edge. A heavy smoke plume emerging from burning Lebanese oil tanks and spreading over adjacent deserts on 17 July 2006 has been observed as an example of such an effect. This study suggests a physical explanation of the observed convection along the edge of the smoke plume, namely the strong thermal contrast resulting from solar heating of the smoke layer.
\end{abstract}

\section{Introduction}

Many ways have been suggested, how atmospheric aerosols can interact with clouds and alter their development and properties (e.g. Twomey, 1974, 1977; Kaufman and Fraser, 1997; Ramanathan et al., 2002; Rudich et al., 2003; Rosenfeld, 2006). The Spinning Enhanced Visible and Infrared Imager (SEVIRI) on the geostationary Meteosat Second Generation (MSG) satellite measures radiation in 11 wavelength bands in the visible and infrared part of the spectrum and with one broadband solar channel with an improved spatial resolution (High Resolution Visible, HRV). This combines the advantages of a fine spatial resolution and of the geostationary orbit, i.e. being able to temporarily resolve dynamical cloud processes. Observing consecutive SEVIRI images enables to study the dynamics of clouds during their lifecy-

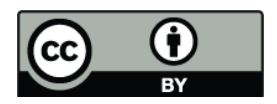

Correspondence to: L. Klüser

(lars.klueser@dlr.de) cles. On 17 July 2006 SEVIRI image loops show a heavy smoke plume emerging from burning Lebanese oil tanks and spreading over the adjacent deserts. Convective clouds can be observed forming at the edge of this smoke plume.

Figure 1 shows the middle-east region as a Red-GreenBlue composite image of the MSG solar channels with central wavelengths at $1.6 \mu \mathrm{m}, 0.8 \mu \mathrm{m}$ and $0.6 \mu \mathrm{m}$, respectively, from 17 July 2006, 12:00 UTC. The smoke plume and convective clouds are marked with arrows in this image.

Section 2 introduces the presented phenomenon in images of the HRV channel and of infrared brightness temperatures and by comparison of the reflectance of the smoke plume and the convective clouds with smoke- and cloud-free images obtained from some days prior to the smoke event. In addition to the consecutive SEVIRI images data from the MODerate resolution Imaging Spectroradiometer (MODIS) on the polar-orbiting Aqua satellite (Barnes et al., 1998) are used for further analysis of the clouds. Section 3 suggests a physical explanation of the observed cloud formation whereas the conclusions are discussed in Sect. 4.

\section{Smoke and cloud observations from SEVIRI and MODIS}

The data mainly used in this study are radiances from the SEVIRI imaging radiometer on the MSG-1 satellite.

The SEVIRI instrument is a 12-channel imager consisting of 11 channels with 'normal' spatial resolution $(3 \mathrm{~km} \times 3 \mathrm{~km}$ at nadir) and one "high resolution" $(1 \mathrm{~km} \times 1 \mathrm{~km}$ at nadir $)$ channel (HRV). The normal resolution channels measure radiation in various wavelength-bands, of which three are in the solar part of the spectrum (between $0.6 \mu \mathrm{m}$ and $1.6 \mu \mathrm{m}$ ), one in the boundary region between solar and terrestrial radiation at a central wavelength of $3.9 \mu \mathrm{m}$ and the resuming seven channels measure the outgoing infrared radiation at central wavelengths between $6.2 \mu \mathrm{m}$ and $13.4 \mu \mathrm{m}$. The HRV

Published by Copernicus Publications on behalf of the European Geosciences Union. 


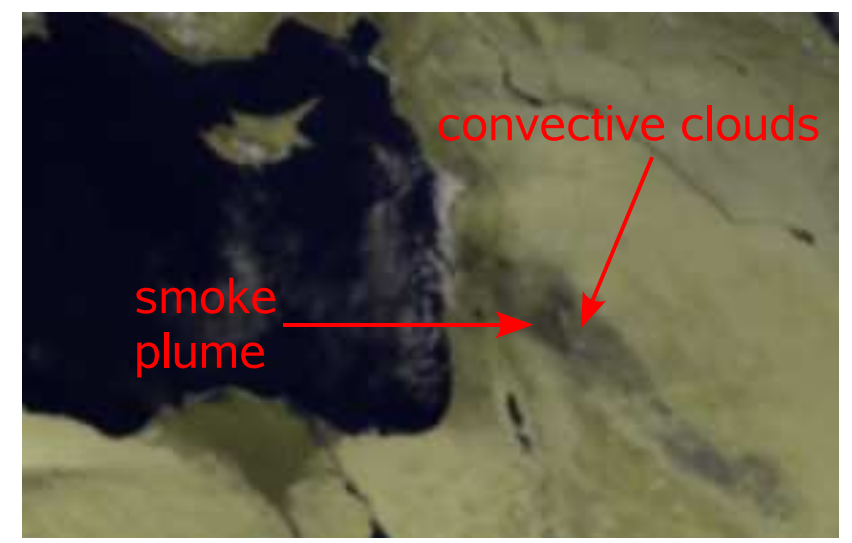

Fig. 1. MSG-SEVIRI image of 17.07.2006, 12:00 UTC. The red, green and blue values are represented by $1.6 \mu \mathrm{m}, 0.8 \mu \mathrm{m}$ and $0.6 \mu \mathrm{m}$ reflectance, respectively. Smoke-plume and convective clouds are marked with arrows.

channel measures reflected sunlight in a much broader wavelength band than the other solar channels of the instrument and covers half of the visible disk of the earth at a much finer spatial resolution. A more detailed description of the satellite and the SEVIRI instrument is given by Schmetz et al. (2002).

Figure 2 shows the reflectance $R$ of the middle-east region on 17 July 2006, obtained by Eq. (1) from the HRV channel radiance for four subsequent hours. The measured radiance $L$ is tranformed to reflectance $R$ by

$R=\frac{\pi L}{\mu_{0} F_{0}}$

where $F_{0}$ is the solar flux in the channel bandwidth and $\mu_{0}$ the cosine of the sun zenith angle.

A major smoke plume emerging from burning Lebanese oil tanks can be identified in Fig. 2 as a dark to black plume spreading inland. Likewise developing convective clouds at the south-eastern edge of the plume can be detected by their high reflectance in the images from 10:00 UTC onward.

An animation of the HRV images from 17 July 2006, which shows the temporal evolution of the observed clouds, is also supplied online: http://www.atmos-chem-phys.net/8/ 2833/2008/acp-8-2833-2008-supplement.zip

The area of the smoke plume (south-eastern part) and convective clouds has been highlighted by a white square consisting of $100 \times 100 \mathrm{HRV}$ pixels (corresponding to about $66 \mathrm{~km}$ in zonal direction and about $136 \mathrm{~km}$ in meridional direction due to the viewing geometry of MSG). With the square corresponding to the same HRV pixels in all four images, one can easily follow the propagation and evolution of the clouds together with the smoke plume. Figure 3 introduces an additional way to visualise the smoke plume and the convective clouds of 17 July 2006. First, a background reference field is generated by selecting the HRV pixels with the lowest reflectance during the period from 01 to 16 July
2006 for 10:00, 11:00, 12:00 and 13:00 UTC respectively. Reference field images, shown in Fig. 10, reveal some cloud shadow structures, mostly confined to the northern half of the image area. Those cloud shadows do not represent the true background reflectance as Eq. (1) does not account for reduction of the surface irradiance reduced by clouds in offnadir viewing geometry. Then the difference in reflectance between the reference field and the corresponding reflectance of 17 July 2006 is calculated according to Eq. (2):

$\Delta R=R_{\text {[smoke event] }}-R_{\text {[reference field] }}$

By this method, the smoke plume can be discriminated in Fig. 3 by negative $\Delta R$ whereas clouds apparent on 17 July 2006 have large positive $\Delta R$. It is obvious, that cloud shadows in the reference field have no strong influence on the appearance of these images. This way of analysis reveals the obvious connection between the smoke plume (dark area) and the convective clouds at the edge. Furthermore some convection takes place above the north-western part of the plume, which is not included in the analysis presented here.

In Fig. $410.8 \mu \mathrm{m}$ brightness temperatures of the region obtained from SEVIRI channel 9 are shown. The brightness temperatures in the area of the smoke plume are reduced to some extend. This reduction of $10.8 \mu \mathrm{m}$ brightness temperatures is further analyzed by means of reference field deviations equivalent to the calculation of $\Delta R$ from Eq. (2). A reference field (for the highlighted area only) has been generated by calculating the mean pixel brightness temperature $(10.8 \mu \mathrm{m})$ from all cloud free days (determined as described in the next passage) of the period also used for the reflectance reference field. Just like for the reflectance, the difference between the brightness temperatures of 17 July 2006 and the reference fields is calculated by Eq. (3):

$\Delta T=T_{\text {[smoke event] }}-T_{\text {[reference field] }}$

$\Delta T$ is shown in Fig. 5 for the highlighted area (confined to the interval $[-20 \mathrm{~K}, 0 \mathrm{~K}]$ for contrast enhancement). Brightness temperatures in smoke- and cloud-free areas are about $1-3 \mathrm{~K}$ above the reference values (not shown), while for the smoke plume $\Delta T$ reaches negative values of about $-10 \mathrm{~K}$. As $10.8 \mu \mathrm{m}$ brightness temperatures have been shown to be only very weakly affected by smoke aerosols (e.g. King et al., 1999; Rudich et al., 2003), this brightness temperature reduction on 17 July 2006 represents a significant reduction in surface temperature below the smoke plume due to the solar heating of the smoke (and hence a lack of solar irradiation at the surface).

The period from which the reference field in Fig. 3 has been generated, has been searched for cloud occurrence in the region of interest. Cloud discrimination follows the method of Rosenfeld and Lensky (1998) in principle. But while these authors chose a reflectance of 0.4 as a general threshold for $0.6 \mu \mathrm{m}$ reflectance, in this study a more tolerant threshold of 0.5 for HRV reflectance is used, due to the 

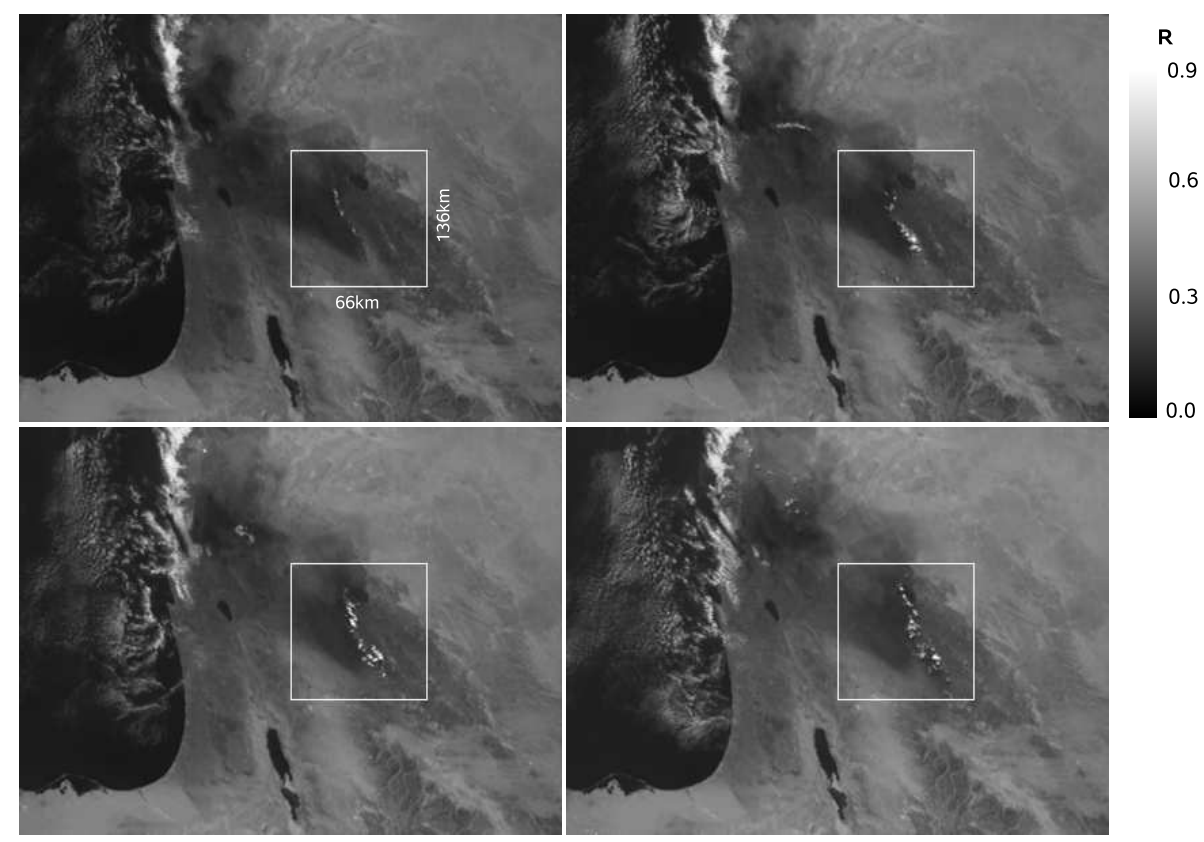

Fig. 2. HRV reflectance of the scene on 17 July 2006. Image acquisition times are 10:00 (top left), 11:00 (top right), 12:00 (bottom left) and 13:00 (bottom right) UTC. For the highlighted area additional cloud cover analysis is provided.

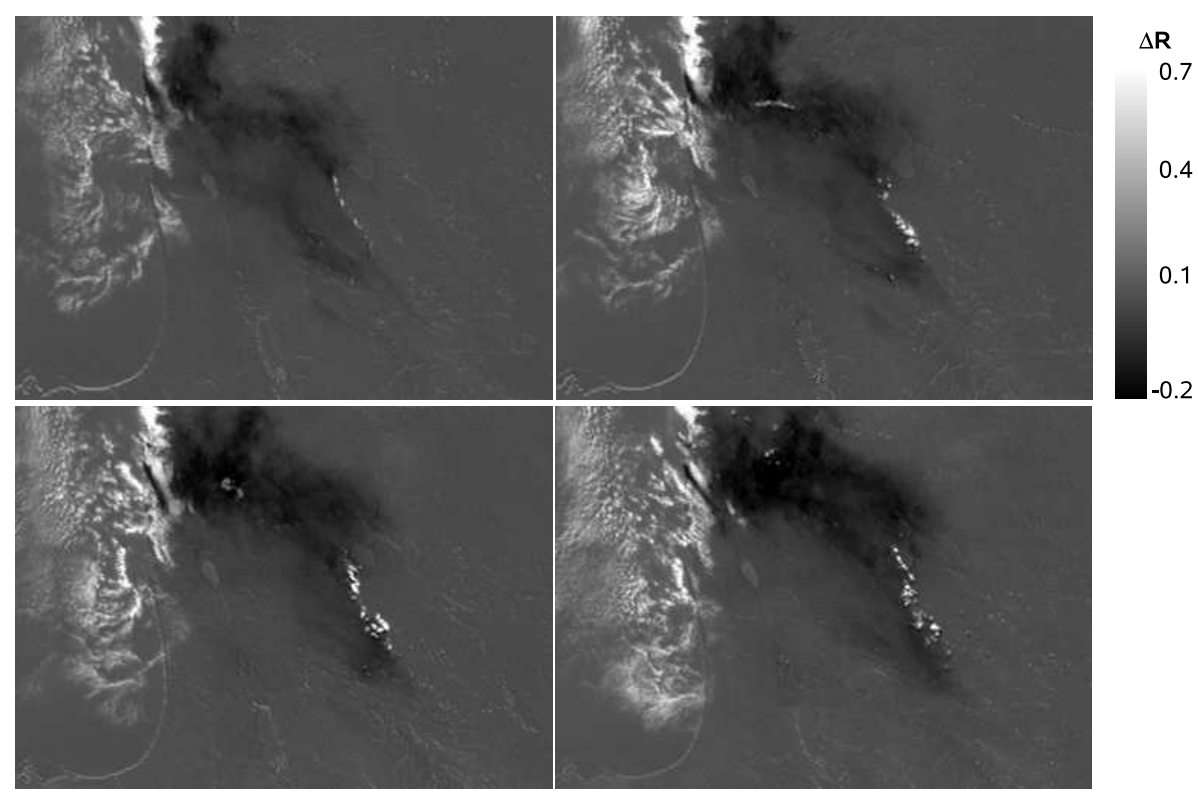

Fig. 3. Difference between HRV reflectance from 17 July 2006 and reference field reflectance. Image acquisition times are the same as in Fig. (2). Negative $\Delta R$ represents the smoke plume, positive $\Delta R$ bright clouds.

high reflectance of bright desert pixels and the broader spectral response function of the HRV channel. By this method some obviously cloudy pixels above the Mediterranean Sea, covered by shallow stratocumulus clouds, are not accounted for, but within the highlighted area the reflectance-threshold of 0.5 led to accurate discrimination of cloudy pixels. Furthermore only HRV pixels with $10.8 \mu \mathrm{m}$ brightness temperatures, which are mapped to co-registered $3 \times 3 \mathrm{HRV}$ pixels, below $295 \mathrm{~K}$ were selected as cloudy. This brightness temperature threshold has proven its appropriateness for the 


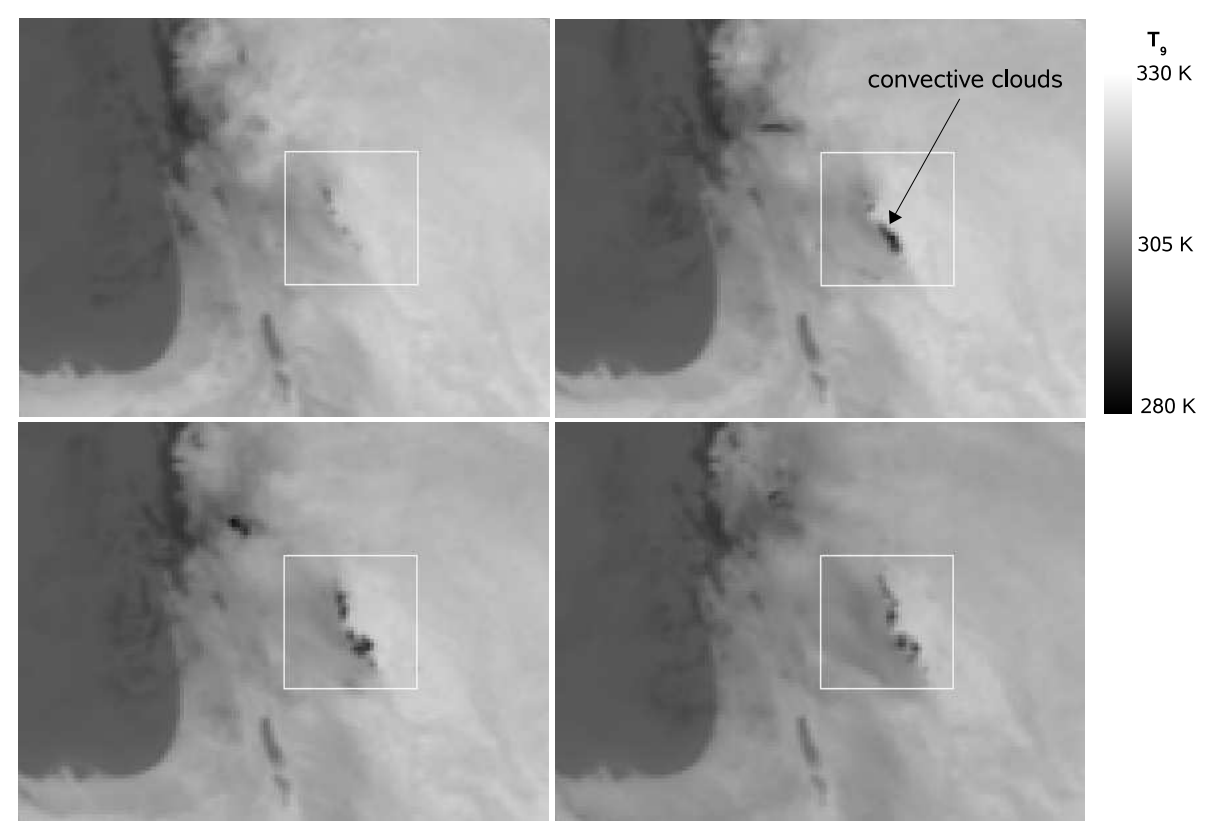

Fig. 4. $10.8 \mu \mathrm{m}$ brightness temperatures from SEVIRI for the same area and times as in Fig. (2) at the coarser "normal" spatial resolution.

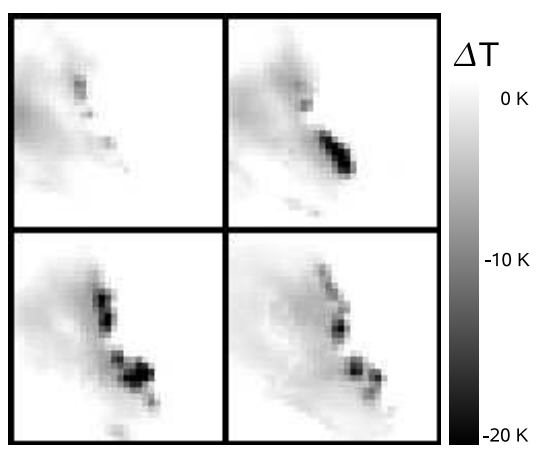

Fig. 5. Difference between $10.8 \mu \mathrm{m}$ brightness temperature from 17 July 2006 and reference brightness temperature for the area highlighted in Fig. (2). Image acquisition times are the same as in the preceding figures. Surface cooling below the smoke plume can be identified by negative $\Delta T$ values.

detection of convective clouds in the region of interest for July 2006, whereas some fog and very shallow cloudfields in the coastal regions to the West remain undetected. Given these two thresholds, convective activity above the considered desert regions in July 2006 can be detected very accurate.

Figure 6 shows the number of days with convective clouds for each HRV pixel of the region. Pixels with more than 3 cloudy days in the smoke-free 16-day analysis period of July 2006 have been set to the value of 3 for visualisation purposes. It is obvious, that convection takes place in the highlighted area in the first half of July 2006, but not very often. Cloud development is more likely in the coastal regions to the north with some pixels there being cloudy all 16 days. Most pixels of the highlighted box, which reveal some cloud appearance, show clouds only on one single day (which moreover is not the same day for all pixels). Furthermore, no characteristic pattern of enhanced cloudiness following the topography is apparent within the highlighted box, which would be the case, if surface features played a role in modulating the cloud formation in the region under the observed conditions.

Figure 7 shows the percentage of pixels detected as being cloudy within the highlighted area from 10:00-13:45 UTC with 15 min temporal resolution. The cross marks represent the mean cloud cover for all smoke-free days with clouds being present (only four days at all) in the first half of July 2006. The dotted lines show the maximum and minimum cloud cover at this time of the day for the smoke free period. The diamond marks (connected with the solid line) in Fig. 7 represent the percentage of cloudy pixels on 17 July 2006 in the highlighted region. Obviously there is a difference in the time of cloud development and their further evolution between the smoke event and smoke free cloud formation. While on 17 July 2006 cloudy pixels are present as early as 10:00 UTC (as can be seen in Fig. 2 in the upper left image) and the cloud cover decreases significantly after 11:30 UTC, on all smoke free days with convective activity it is just the other way round: significant cloud development normally starts about 11:00 UTC, if at all, and the cloud cover keeps raising to higher values at least until 


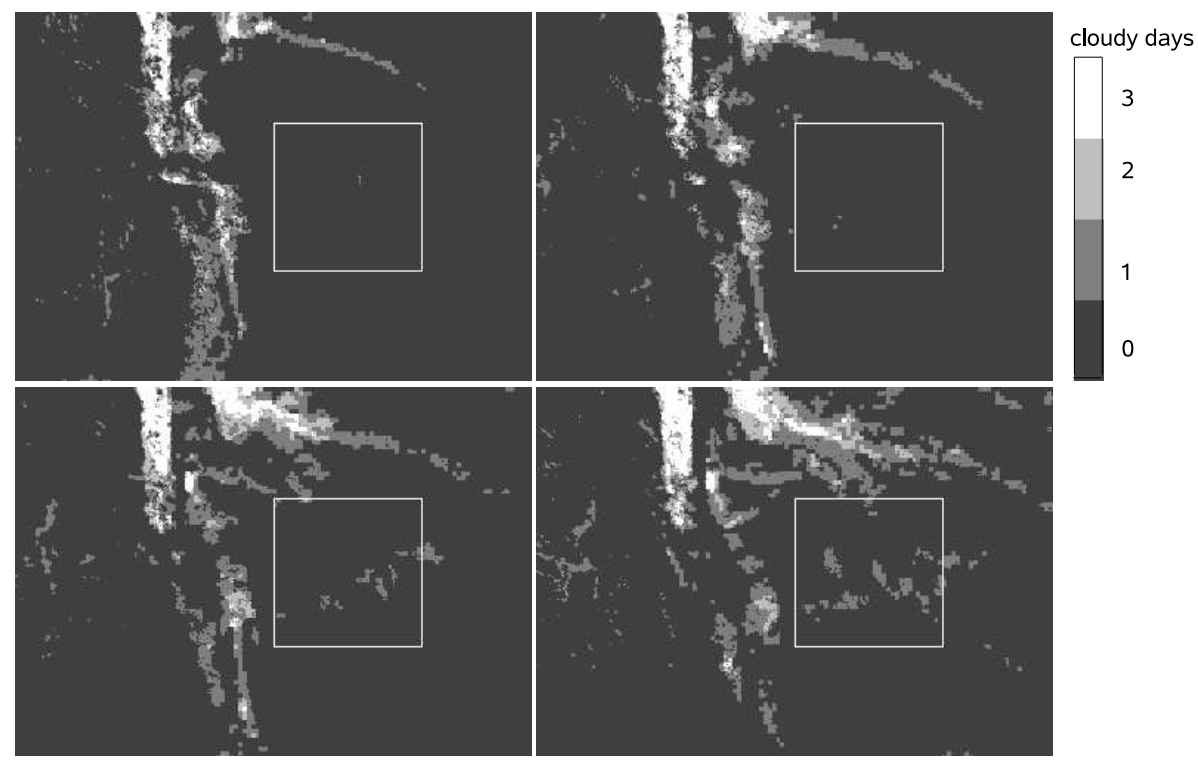

Fig. 6. Number of days with pixels being cloud covered during 1 July-16 July 2006 for the area and times shown in above figures. White pixels are cloud covered on more than two days.

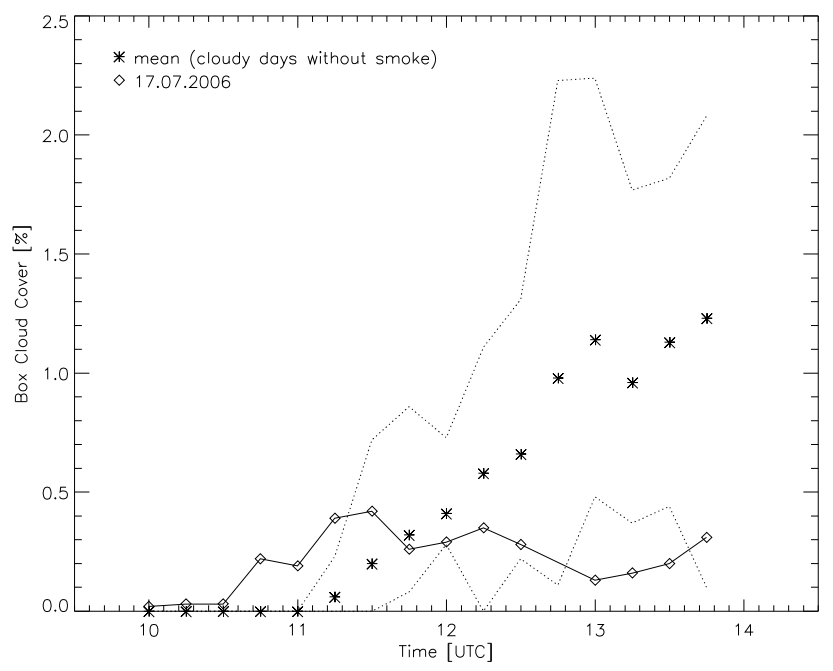

Fig. 7. Cloud cover timeseries of the area highlighted in Fig. 2 for 17 July 2006 and a smoke-free 16 day period prior to this date (dotted lines represent maximum and minimum values of the smokefree period).

about 13:00-14:00 UTC. Figure 6 supports this later convection development under smoke free conditions with the highest number of pixels with at least one cloudy day being present at 13:00 UTC in the highlighted box. Thus analysis of the time of cloud development also strongly supports that the clouds observed on 17 July 2006 are connected directly to the presence of the smoke plume.

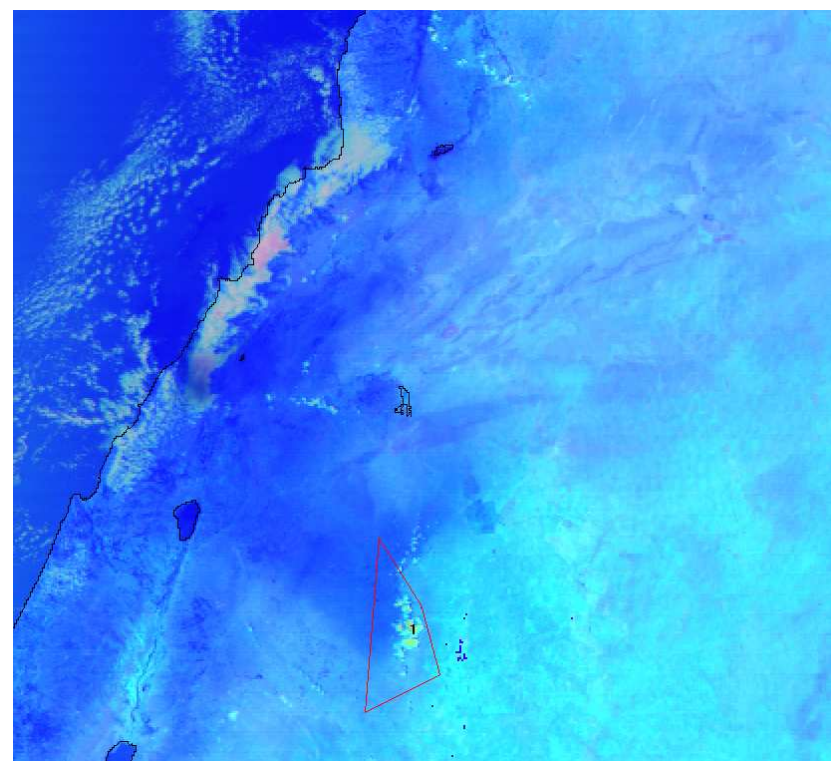

Fig. 8. Aqua MODIS image of the presented scene (image acquisition time is 10:50 UTC). RGB values are represented by $0.6 \mu \mathrm{m}$ reflectance, $3.9 \mu \mathrm{m}$ reflectance and $11 \mu \mathrm{m}$ brightness temperature, respectively. From the highlighted area, $T$ and $r$ are inferred for cloudy pixels.

Further insights into the clouds forming at the edge of the smoke plume can be gained through Aqua MODIS data from 17 July 2006. Figure 8 shows the scene at 10:50 UTC as seen by MODIS. The image generation scheme used here and its 


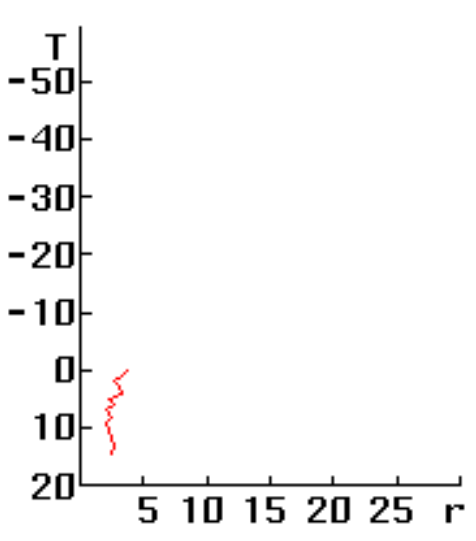

Fig. 9. $T$ (in ${ }^{\circ} \mathrm{C}$ ) versus $r$ (in $\mu \mathrm{m}$ ) for cloudy pixels inferred from the highlighted area in Fig. 8.

physical interpretation is described in Rosenfeld and Lensky (1998). For cloudy pixels within the area surrounded by the red line in Fig. $811 \mu \mathrm{m}$ brightness temperature $(T)$ and cloud droplet effective radius $r$ are retrieved as described in Rosenfeld and Lensky (1998). The $T-r$ graph is shown in Fig. 9, brightness temperatures in this graph are in ${ }^{\circ} \mathrm{C}$ and effective radius is in $\mu \mathrm{m}$. These data first of all reveal extremely small cloud droplet effective radii $(<5 \mu \mathrm{m})$ for all cloud covered pixels, actually being at the lower limit of the retrieval algorithm, which is $2 \mu \mathrm{m}$. This extremely small cloud droplet size indicates highly polluted air supplying a large number of small cloud condensation nuclei (CCN) and thus leading to very small cloud droplets, an effect first described by Twomey (1974).

Furthermore Fig. 9 reveals cloud base temperatures (by means of highest brightness temperatures of cloudy pixels within the analysis area, see Rosenfeld and Lensky (1998)) of about $285 \mathrm{~K}-286 \mathrm{~K}$ for the convection along the edge of the smoke plume, while cloud top temperatures, reaching values of about $273 \mathrm{~K}$ at the time of the MODIS image acquisition, obviously stay above the freezing level.

\section{Convective cloud formation by the presence of a smoke plume}

Formation of convective clouds in relationship with oil fire plumes was described e.g. by Rudich et al. (2003). Those authors detected convective clouds above smoke plumes emerging from Kuwait oil fires in the year 1991 by analysing images obtained from the Advanced Very High Resolution Radiometer (AVHRR).

Inspection of the figures in Rudich et al. (2003) reveals that smaller convective clouds also were formed at the periphery of the smoke plumes, probably by a mechanism similar to that proposed here. But the clouds mainly investigated in Rudich et al. (2003) developed in the middle of the Kuwait plumes and so were probably formed by a different mechanism. Thus another mechanism for the formation of convective clouds in a smoke-polluted environment is suggested here.

From the MODIS scene a reduction of surface brightness temperature under the smoke plume of about $12 \mathrm{~K}$ can be inferred, which corresponds to the findings from Fig. 5. This temperature reduction beneath the smoke together with the reduced reflection of solar radiation observed in Fig. 3 indicates strong solar heating within the smoke plume, as stated above. Given this solar heating of the smoke, a strong thermal contrast between the hot air of the smoke plume and the warm smoke free air exists, which induces a general rising motion of the smoky air. Along the line of the highest horizontal temperature gradient convection is observed, which obviously benefits from the high amount of CCN present in the highly polluted air.

The smoke seems to be darkest around the clouds (see Fig. 3 and Fig. 4). This probably indicates the deepening of the smoky layer where convergence occurs and the top of the smoky layer rises. The strongest rising is topped by the convective clouds, which are fed by it. As the horizontal temperature gradient is maintained by the solar heating of the smoke even after invocation of the convection and additional warming through the release of latent heat takes place, shallow convective clouds develop in an environment, in which cloud formation without the presence of a smoke plume would be (and actually is) suppressed.

\section{Conclusions}

A major smoke plume spreading over middle-east desert regions on 17 July 2006 has been detected and analyzed in the data of the SEVIRI instrument on the geostationary MSG satellite. Imagery of reflected solar radiation at the fine spatial resolution of the HRV channel gives evidence that the spreading smoke induces convective clouds. This conclusion is strongly supported by comparison of HRV reflectance of the day of the smoke event with cloud-free reference reflectance of a smoke-free 16 day period before and by the early cloud formation time compared to cloud formation times on smoke-free days in the region during July 2006. The cloud formation and evolution times are quantitatively determined by regional cloud cover of 17 July 2006 and compared with the smoke-free period. Furthermore extremely small cloud droplet effective radius can be inferred from analysing MODIS data of the scene. The small droplet size indicates a very large number of cloud condensation nuclei within the observed clouds. This supports the inference that the rising motion within the smoky air produced these clouds. Cloud top and base temperatures are also determined for the MODIS scene. Cloud base temperature is high to the extent that is consistent with the rising air that formed the clouds originating at the boundary layer. This rising motion at the 

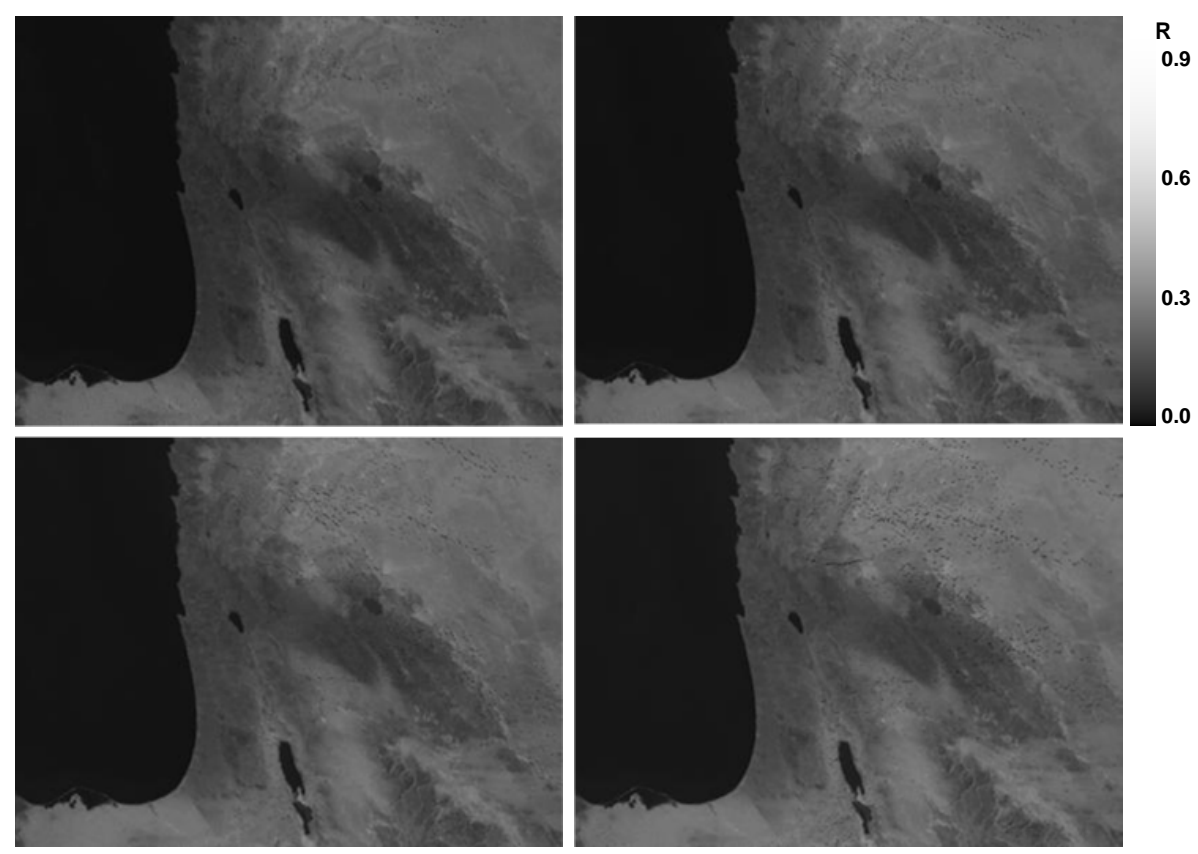

Fig. 10. HRV reference field determined from the period 01 to 16 July 2006. Image acquisition times are the same as in Fig. 2.

edge of the smoke plume may result from the sharp horizontal thermal contrast between the smoky and the smoke free air masses.

Smoke plumes from biomass burning on the African continent during the dry season have been searched for similar cloud structures, but none have been found so far. Thus we conclude that the smoke plume induced convective clouds observed in this study are a result of the rather special conditions of the presented event. Given these conditions, i.e. soot from burning oil, which is much darker than smoke from forest fires and thus is subject to stronger solar heating, yielding to high absorption of solar radiation within the smoke plume, a strong horizontal temperature gradient at its very edge is suggested to induce the cloud formation.

These conclusions give evidence, that absorption of solar radiation by aerosols not only can act to suppress cloud formation (e.g. Kaufman and Fraser, 1997; Ackerman et al., 2000; Koren et al., 2004) but also to induce convective clouds in suitable environments. To fully understand the dynamics of the presented effect, our findings may hopefully encourage experts in small scale cloud resolved modeling to study the described plume edge induced cloud formation.

Acknowledgements. The authors want to thank three anonymous referees for their useful comments.

Edited by: T. Garrett

\section{References}

Ackerman, A. S., Toon, O. B., Stevens, D. E., Heymsfield, A. J., Ramanathan, V., and Welton, E. J.: Reduction of tropical cloudiness by soot, Science, 288, 1042-1047, 2000.

Barnes, W. L., Pagano, T. S., and Salomonson, V. V.: Prelaunch characteristics of the Moderate Resolution Imaging Spectroradiometer (MODIS) on EOS-AM1, IEEE T. Geosci. Remote, 36, 1088-1100, 1998.

Hobbs, P. V., Reid, J. S., Kotchenruther, R. A., Ferek, R. J., and Weiss, R.: Direct radiative forcing by smoke from biomass burning, Science, 275, 1777-1778, 1997.

Kaufman, Y. J. and Fraser, R. S.: The effect of smoke particles on clouds and climate forcing, Science, 277, 1636-1639, 1997.

King, M. D., Kaufman, Y. J., Tanre, D., and Nakajima, T.: Remote sensing of tropospheric aerosols from space: past, present, and future, B. Am. Meteorol. Soc., 80, 2229-2259, 1999.

Koren, I., Kaufman, Y. J., Remer, L. A., and Martins, J. V.: Measurement of the effect of Amazon smoke on inhibition of cloud formation, Science, 303, 1342-1345, 2004.

Ramanathan, A., Crutzen, P. J., Kiehl, J. T., and Rosenfeld, D.: Aerosols, climate, and the hydrological cycle, Science, 294, 2119-2124, 2001.

Rosenfeld, D. and Lensky, I. M.: Satellite-based insights into precipitation formation processes in continental and maritime convective clouds, B. Am. Meteorol. Soc., 79, 2457-2476, 1998.

Rosenfeld, D.: Aerosol-cloud interactions control of earth radiation and latent heat release budgets, Space Sci. Rev., 125, 149-157, 2006.

Rudich, Y., Sagi, A., and Rosenfeld, D.: Influence of the Kuwait oil fire plume (1991) on the microphysical development of clouds, J. Geophys. Res., 108(D15), 4478, doi:10.1029/2003JD003472, 
2003.

Schmetz, J., Pili, P., Tjemkes, S., Just, D., Kerkmann, J., Rota, S., and Ratier, A.: An Introduction to Meteosat Second Generation (MSG), B. Am. Meteorol. Soc., 83, 977-992, 2002.

Twomey, S.: Pollution and the planetary albedo, Atmos. Environ., 8, 1251-1256, 1974.
Twomey, S.: Atmospheric aerosols, Elsevier, Amsterdam, Netherlands, 1977.

Wielicki, B. A., Harrrison, E. F., Cess, R. D., King, M. D., and Randall, D. A.: Mission to planet earth: Role of clouds and radiation in climate, B. Am. Meteorol. Soc., 76, 2125-2153, 1995. 